\title{
Untargeted Metabolomics Profiling of High Beta Carotene Cassava with respect to Postharvest Physiological Deterioration
}

\author{
Ngozi L. Edoh ${ }^{1,2}$, Ukpabi J. Ukpabi ${ }^{2}$ \& John O. Igoli ${ }^{1,3}$ \\ ${ }^{1}$ Center for Food Technology and Research, Benue State University Makurdi, Nigeria \\ ${ }^{2}$ National Root Crops Research Institute, Umudike, Nigeria \\ ${ }^{3}$ Department of Chemistry, University of Agriculture Makurdi, Nigeria \\ Correspondence: Ngozi Edoh, Biotechnology Program, National Root Crops Research Institute Umudike, \\ Nigeria. Tel: 130-1383-7405. E-mail: ngoziedoh@gmail.com
}

Received: June 8, 2021

doi:10.5539/jfr.v10n6p1
Accepted: October 23, $2021 \quad$ Online Published: October 25, 2021

URL: https://doi.org/10.5539/jfr.v10n6p1

\begin{abstract}
Cassava roots undergo postharvest physiological deterioration (PPD), and for most varieties it sets in within 72 hours of harvest. An untargeted metabolomics approach combined with a data-driven approach for statistical analysis was used to characterize and profile high beta-carotene cassava varieties with the aim of identifying any relevant metabolite changes that occur during PPD. Sixteen cassava root samples from four cassava lines were planted in a greenhouse and harvested after four months. The samples included four of 2 conventionally bred beta carotene cassava varieties - UMUCASS 38, UMUCASS 45 and four of 2 transgenic high beta carotene cultivars - EC20-7 and EC20-8 cassava lines. Extracts of fresh cassava roots from 20-100 mg tissues were used for the analyses and data were processed using Elements for Metabolomics software. Starch and lipid metabolites were the major constituents which may help explain the observed differences in starch and dry matter content among the varieties. The results provide further insight in the understanding of PPD and suggestions on controlling this deterioration in cassava are made.
\end{abstract}

Keywords: metabolomics, cassava, postharvest physiological deterioration, carotenoids, transgenic cassava

\section{Introduction}

Cassava (Manihot esculenta Crantz) is an important staple crop in the tropical parts or countries of the world. The roots are starchy tubers, with several attributes such as withstanding droughts, cheap, available and affordable, resistant to pests and easy to cultivate. Although it is a valuable source of energy, the nutritional composition is deficient in some essential nutrients vitamins and minerals (Edoh et al., 2014). Conventional breeding and genetic modification techniques are presently being used to improve the beta-carotene content of cassava for a sustainable solution to vitamin A deficiency (VAD) in Africa (Bayoumi et al., 2010). Carotenoids are natural terpenoids responsible for the distinctive yellow, orange and some reddish colours (as well as several aromas) in leaves, fruits, vegetables and flowers of plants (Fraser et al., 2004). Carotenoids are biosynthesized and they participate in various biological processes in plants, such as photosynthesis, photo-morphogenesis, photo-protection, physical development (Nisar et al., 2015; Cao et al., 2015) and the production of carotenoid-derived phytohormones, including abscisic acid and strigolactone (Fraser et al., 2004). The major plant carotenoids are antheraxanthin, capsanthin, $\alpha$-carotene, $\beta$-carotene, $\varepsilon$-carotene, $\gamma$-carotene, $\alpha$-cryptoxanthin, lutein, lycopene, neoxanthin, and zeaxanthin (Howitt et al., 2006). Beta-carotene is a major precursor of vitamin A (retinol) in humans (Grune et al., 2010) and it is an important micronutrient in humans (Burri, 1997). Diets containing carotene-rich vegetables, fruits and roots are useful in protection against cancer, heart diseases, cataracts and ultraviolet-induced skin damage (Carvalho et al., 2016). The development of high yield $\beta$-carotene crops such as golden rice, yellow cassava and orange sweet potato could provide the recommended daily intake of vitamin A for malnourished children and help combat vitamin A deficiency-induced mortality and morbidity. Beta-carotene content is also associated with reduction in post-harvest physiological deterioration of cassava roots due to the oxidative nature of carotenoids (Sanchez et al., 2006). Postharvest physiological deterioration (PPD) is increasingly important due to urbanization in producing countries and the resultant increase in distance and time between farm and market or processing centers. There have been several estimates of the economic impact of PPD. Estimated losses due to PPD in cassava range from 5-25\% of the total expected value of the crop 
(Zidenga, 2012). The physiological changes that occur during PPD are due to the oxidation of phenolic compounds and involve the formation of reactive oxygen species (ROS). Alterations in gene expression, protein synthesis and the accumulation and oxidation of a range of secondary metabolites (Beeching et al., 2009). Metabolites represent the outcome of gene expressions and define the biochemical phenotype of a cell, tissue, organ or organism. Small metabolites include the intermediates and end products of metabolism, and they include primary (sugars, amino acids, fatty acids and organic acids) and secondary metabolites (phenyl propanoids, terpenes, flavonoids and alkaloids) (Commisso et al., 2013). Recent advances in metabolomics have enabled untargeted profiling of thousands of metabolites. Metabolomics can characterize the dynamic metabolome, showing changes in the abundance of small molecules during development and in response to external stresses (Vinayavekhin \& Saghatelian, 2010). In this study, an untargeted metabolomics combined with a data-driven approach for statistical analysis was used to profile conventionally bred and transgenic high beta-carotene cassava varieties to identify the relevant metabolite changes that take place in cassava varieties.

\section{Method}

All reagents were of analytical grade unless otherwise stated. HPLC grade solvents were obtained from J.T. Baker and Sigma-Aldrich USA. LC-MS grade water was obtained from Honeywell part of Thermo Fisher Scientific, USA. Cassava samples were analyzed for their metabolite content using liquid chromatography-high resolution mass spectrophotometer (LC-HRMS) and hydrophilic interaction liquid chromatography (HILIC) Q-Exactive. All experiments were carried out at Donald Danforth Plant Science Center (DDPSC) St. Louis, Missouri USA in collaboration with the National Root Crops Research Institute (NRCRI), Umudike, Nigeria.

\subsection{Sample Collection}

Identification and selection of two conventionally bred (UMUCASS) high beta-carotene cassava or yellow cassava stakes were carried out with the assistance of the Genetic Resource Unit and Cassava Programme of NRCRI, Umudike, Nigeria. Collection of two transgenic bred (EC 20) high beta carotene cassava stakes and wild type (TME 7) were with the assistance of the International Institute for Crop Improvement (IICI) Department of Donald Danforth Plant Science Center (DDPSC) St. Louis, Missouri USA. These cassava stakes were planted in a greenhouse at the Donald Danforth Plant Science Center, St. Louis Missouri, USA and harvested four months after planting.

\subsection{Sample Preparation}

Twenty (20) mg of ground freshly harvested cassava root samples were weighed for each variety. Two hundred (200) $\mu \mathrm{L}$ of $80 \%$ methanol was added to the samples. The samples were mixed thoroughly using vortex for 1 minute before centrifuge at $13.2 \mathrm{rpm}$ for $5 \mathrm{~min}$ at $4{ }^{\circ} \mathrm{C}$. The supernatants were carefully removed and filtered with polyether-sulfone (PES) spin-filters before loading onto the LC-HRMS.

\subsection{Dry Matter Content}

The dry matter content of the cassava varieties was determined by a modified method of Asare, (2004) using a freeze drier. The dry matter content was determined from the difference between the fresh and dry weights of the samples. Dry matter was expressed as a percentage of dry weight relative to fresh weight (Morante et al. 2010).

\subsection{Starch and Sugar Analysis}

The starch content of the experimental fresh cassava roots were determined using methods for Carbohydrates in Handbook of Chromatography (Churms, 1982) while the iodine-starch test was determined following the protocol in the Advanced Bio imaging Laboratory of Donald Danforth Plant Science Center St. Louis, USA.

\subsection{Chromatographic Analyses}

High performance chromatographic (Fig. 1) analyses were performed with Zic-HILIC (Higgins Analytical INC USA) using a $150 \times 0.5 \mathrm{~mm}$ column and a reverse phase (PLRPS) $100 \times 0.5 \mathrm{~mm} \mathrm{C}_{18}$ column on a Thermo Scientific Q-Exactive liquid chromatography coupled to a high-resolution mass spectrometer (LC-HRMS) respectively. Eluent A was $10 \mathrm{mM} \mathrm{NH}_{4} \mathrm{HCO}_{3}$ (v/v) and $95 \% \mathrm{ACN}$ and eluent $\mathrm{B}$ was $10 \mathrm{mM} \mathrm{NH}_{4} \mathrm{HCO}_{3}(\mathrm{v} / \mathrm{v})$. Under gradient conditions with initial condition of $100 \% \mathrm{~B}$ and $0 \% \mathrm{~A}$ in $30 \mathrm{~min}$, and back to the initial condition for re-equilibration, the analysis was carried out at a flow rate of $0.15 \mathrm{~mL} / \mathrm{min}$ at room temperature. The raw data from Q-Exactive were processed using Elements for Metabolomics software. 


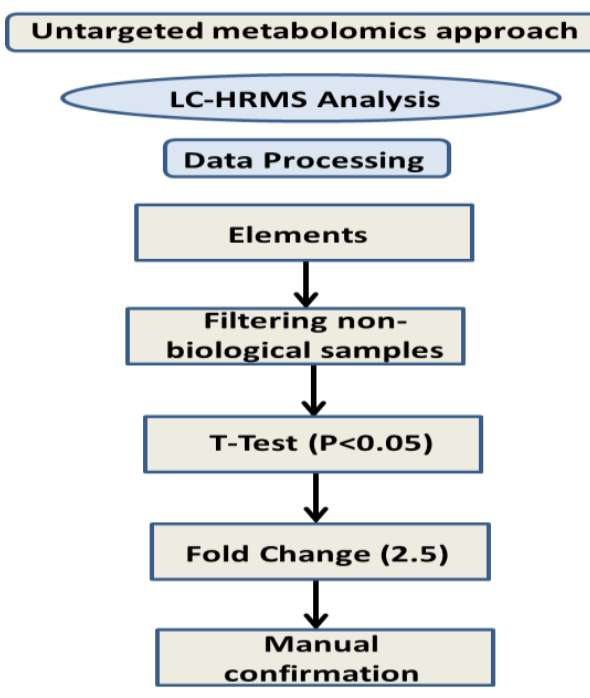

Figure 1. Flowchart of untargeted metabolomics approach used in this study

\subsection{Statistics and Data Analysis}

Statistical significance for all analysis carried out in triplicate was established using one-way analysis of variance (ANOVA), and data were reported as mean \pm standard deviation. Mean comparison and separation was established using Duncan Multiple Range Test $(P<0.05)$

\section{Results}

\subsection{Dry Matter Content (DMC)}

The dry matter content of the cassava roots is presented in Table 1

Table 1. Dry matter content of the experimental cassava roots

\begin{tabular}{ll}
\hline Variety & Mean $(\%)$ \\
\hline UMUCASS 38 & $35.76 \pm 2.37^{\mathrm{b}}$ \\
UMUCASS 45 & $39.75 \pm 1.05^{\mathrm{b}}$ \\
TME-7 & $39.35 \pm 5.64^{\mathrm{b}}$ \\
EC20-7 & $24.55 \pm 2.19^{\mathrm{a}}$ \\
EC20-8 & $23.90 \pm 0.75^{\mathrm{a}}$ \\
\hline
\end{tabular}

Values are mean of triplicate determination, values with the same letter are not significantly different $(P=0.05)$ using Duncan Multiple Range Test.

UMUCASS $38=$ Conventional 1 ; UMUCASS $45=$ Conventional 2

EC20-7 = Transgenic 1; EC20-8 =Transgenic 2

TME-7 = Wild Type

\subsection{Starch and Sugar Content}

The starch and sugar contents of the cassava roots on dry matter basis is presented in Table 2.

Table 2. Starch and sugar content of the cassava roots on dry matter basis

\begin{tabular}{llll}
\hline Variety & Starch $(\%)$ & Glucose $(\%)$ & Fructose $(\%)$ \\
\hline UMUCASS 38 & $72.65 \pm 3.01^{\mathrm{b}}$ & $1.07 \pm 0.10^{\mathrm{b}}$ & $0.55 \pm 0.24^{\mathrm{a}}$ \\
UMUCASS 45 & $75.75 \pm 1.9^{\mathrm{bc}}$ & $0.65 \pm 0.08^{\mathrm{a}}$ & $0.47 \pm 0.28^{\mathrm{a}}$ \\
TME-7 & $77.09 \pm 0.09^{\mathrm{c}}$ & $1.06 \pm 0.13^{\mathrm{b}}$ & $0.44 \pm 0.23^{\mathrm{a}}$ \\
EC20-7 & $54.10 \pm 2.55^{\mathrm{a}}$ & $1.05 \pm 0.20^{\mathrm{b}}$ & $0.47 \pm 0.25^{\mathrm{a}}$ \\
EC20-8 & $52.25 \pm 1.01^{\mathrm{a}}$ & $1.19 \pm 0.05^{\mathrm{b}}$ & $0.76 \pm 0.13^{\mathrm{a}}$ \\
\hline
\end{tabular}

Values are mean of triplicate determinations, values with the same letter are not significantly $(P>0.05)$ different using Duncan Multiple Range Test. 
UMUCASS $38=$ Conventional 1 ; UMUCASS $45=$ Conventional 2

EC20-7 = Transgenic 1; EC20-8 =Transgenic 2

\subsection{Microscopic Distribution of Starch}

Figure 2 show the distribution of starch granules in EC-20 and TME-7 roots

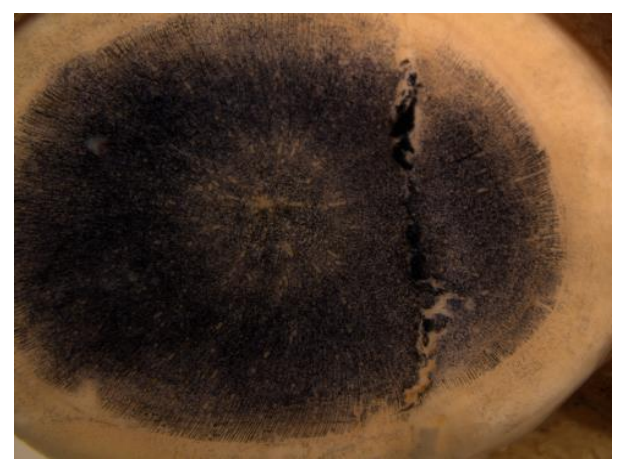

Figure 2. Microscopic view of stained EC20-7 transgenic yellow cassava variety

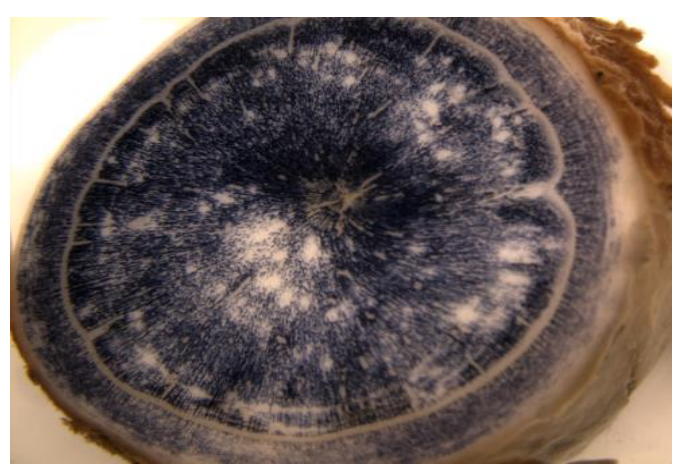

Figure 3. Microscopic view of stained TME-7 (Wild Type) cassava variety

\subsection{Untargeted Metabolites of EC-20 and TME-7using HILIC}

The result of untargeted metabolites of EC-20 and TME-7using HILIC is presented Table 3.

Table 3. Untargeted metabolites in fresh cassava roots comparing EC-20 and TME-7 roots using HILIC

\begin{tabular}{lll}
\hline Metabolite & Fold Change & Molecular Formula \\
\hline Monogalactosyldiacylglycerol & 719.00 & $\mathrm{C}_{35} \mathrm{H}_{66} \mathrm{O}_{10}$ \\
Maltotriose & 4.11 & $\mathrm{C}_{18} \mathrm{H}_{32} \mathrm{O}_{16}$ \\
Digalactosyl diacylglycerol (DGDG) & 3.30 & $\mathrm{C}_{43} \mathrm{H}_{80} \mathrm{O}_{15}$ \\
Inosine & -3.49 & $\mathrm{C}_{10} \mathrm{H}_{12} \mathrm{~N}_{4} \mathrm{O}_{5}$ \\
Phosphatidylcholine & -4.08 & $\mathrm{C}_{44} \mathrm{H}_{84} \mathrm{NO}_{8} \mathrm{P}$ \\
\hline
\end{tabular}

\subsection{Untargeted Metabolites of UMUCASS and TME-7}

The result of untargeted metabolites of UMUCASS and TME-7using HILIC is presented in Table 4.

Table 4. Untargeted metabolites in fresh cassava roots comparing UMUCASS and TME-7 roots using HILIC

\begin{tabular}{lll}
\hline Metabolite & Fold Change & Molecular Formula \\
\hline Lysophosphatidylcholine & 4.20 & $\mathrm{C}_{26} \mathrm{H}_{50} \mathrm{NO}_{7} \mathrm{P}$ \\
Diacylglyceryl trimethylhomoserine & 3.83 & $\mathrm{C}_{40} \mathrm{H}_{67} \mathrm{NO}_{7}$ \\
Celastrol & -3.10 & $\mathrm{C}_{29} \mathrm{H}_{38} \mathrm{O}_{4}$ \\
Inosine & -3.32 & $\mathrm{C}_{10} \mathrm{H}_{12} \mathrm{~N}_{4} \mathrm{O}_{5}$ \\
\hline
\end{tabular}




\subsection{Untargeted Metabolites of EC-20 and TME-7 RPLC}

The result of untargeted metabolites of EC-20 and TME-7using RPLC is presented in Table 5.

Table 5. Untargeted metabolites in fresh cassava roots comparing EC-20 and TME-7 roots using RPLC

\begin{tabular}{lll}
\hline Metabolite & Fold Change & Molecular Formula \\
\hline Digalactosyl diglyceride & 664.33 & $\mathrm{C}_{53} \mathrm{H}_{84} \mathrm{O}_{15}$ \\
Digalactosyl diglyceride & 654.00 & $\mathrm{C}_{53} \mathrm{H}_{86} \mathrm{O}_{15}$ \\
Digalactosyl diglyceride & 598.00 & $\mathrm{C}_{53} \mathrm{H}_{88} \mathrm{O}_{15}$ \\
Diacylglyceryl trimethylhomoserine & 590.00 & $\mathrm{C}_{46} \mathrm{H}_{73} \mathrm{NO}_{7}$ \\
linoleic acid & 3.14 & $\mathrm{C}_{18} \mathrm{H}_{32} \mathrm{O}_{2}$ \\
Dihydro-kaempferol & 3.03 & $\mathrm{C}_{15} \mathrm{H}_{12} \mathrm{O}_{6}$ \\
Salicylic acid & 2.99 & $\mathrm{C}_{7} \mathrm{H}_{6} \mathrm{O}_{3}$ \\
Aspartate & -3.00 & $\mathrm{C}_{9} \mathrm{H}_{16} \mathrm{~N}_{2} \mathrm{O}_{5}$ \\
\hline
\end{tabular}

\section{Discussion}

The percentage dry matter content (DMC) of TME-7 was the highest $(42.60 \%)$ among the cassava varieties and this was significantly $(\mathrm{P}<0.05)$ different from the EC20-7 $(24.23 \%)$ and EC20-8 $(23.18 \%)$ respectively. The percentage DMC of UMUCASS 38 (35.61\%) and UMUCASS $45(36.96 \%)$ varieties were significantly $(\mathrm{P}<0.05)$ different from EC20-7 (24.23 \%), and EC20-8 (23.18 \%) varieties. There was no significant $(\mathrm{P}>0.05)$ difference observed in the DMC of TME-7 (42.60 \%), UMUCASS 45 (35.61\%) and UMUCASS 38 (36.96\%) varieties. Dry matter content relates to good cooking quality. Higher dry matter content suggests better cooking quality of the flour that would be produced from these cassava varieties in addition to their longer shelf life (Eleazu et al., 2012). A positive correlation between dry matter and PPD was reported by Uarrota et al, (2015), and implies that varieties with high level of dry matter are more prone to suffer from PPD.

The starch content of the experimental cassava varieties indicate that EC20-8 $(52.25 \%)$ variety had the least percentage followed by EC20-7 (54.10\%) which were significantly $(\mathrm{P}<0.05)$ different from the starch content of UMUCASS 38 (72.65 \%), UMUCASS 45 (75.75 \%) and TME-7 (77.09 \%) varieties. A significant $(\mathrm{P}<0.05)$ difference was observed in the glucose content of UMUCASS 45 (0.65 \%) and UMUCASS 38 (1.07 \%), EC20-7 $(1.05 \%)$, EC20-8 (1.19\%) and TME-7 (1.06 \%). The fructose content of the experimental cassava varieties used in this study showed no significant $(\mathrm{P}>0.05)$ difference among the varieties. The starch and sugar content show that TME-7 had the highest starch content which corroborates the findings of Aristizabal and Sánchez, (2007). Also, the distribution of starch granules in the transgenic roots (Fig. 2) seem to be confined between the phloem and xylem bundles while starch distribution in the whitish TME-7 roots Fig.3) were more widely distributed up to the sclerenchyma region of the root cortex. Postharvest physiological deterioration is associated with vascular streaking or discolouration and Sánchez et al., (2006) observed a positive correlation between high starch content and the degree of PPD.

\subsection{Untargeted Metabolites of EC-20 and TME-7}

The untargeted metabolites of the fresh cassava roots for EC-20, TME-7 and EC-20 roots using HILIC are given in Table 3. Monogalactosyl-diacylglycerol (MGDG), maltotriose, and diagalactosyl-diacylglycerol (DGDG) were identified as the upregulated (>2.0 folds) metabolites in TME-7 varieties. Monogalactosyl-diacylglycerol and diagalactosyl-diacylglycerol are galactolipids which have been recognized as principal lipid components in photosynthesis (Block et al., 1983). Their quantity is mostly elevated in thylakoid membranes, in which MGDG exemplify $50 \%$ of the polar lipids. MGDG is well-maintained in practically all photosynthetic organisms, and it is one of the most abundant natural polar lipid in plants (Dormann and Benning, 2002). It is highly accumulated in the chloroplast membrane and also an important constituent of the thylakoid membranes (Masuda, 2011). Studies suggest its connectivity with chlorosome, a light-harvesting compound; and MGDG biosynthesis has been recognized in each photosynthetic organism to achieve photosynthesis under different environmental conditions (Masuda, 2011). Digalactosyldiacylglycerol is a typical membrane lipid of oxygenic photosynthetic organisms. DGDG is also important for the assembly and function of photosynthetic complexes in the thylakoid membranes (Dormann and Benning, 2002, Sakurai et al., 2007). There are reports on the utilization of maltotriose and the possible relationship between maltotriose uptake and metabolism. Although maltotriose is considered a fermentable sugar, and this has been recently demonstrated for several brewer and baker strains (Londesborough, 2001). Maltotriose is mainly respired, which might explain its incomplete consumption at the final stage of oxygen-limited fermentation processes (Zastrow, 2000). 


\subsection{Untargeted Metabolites of UMUCASS and TME-7}

The untargeted metabolites of the fresh cassava roots for UMUCASS, TME-7 and UMUCASS varieties using HILIC are given in Table 4. Lysophospholipids and diacylglyceryltrimethyl homoserine (DGTS) were identified as the upregulated (>2.0 folds) metabolites in TME-7 varieties. Lysophospholipids are polyunsaturated fatty acids synthesized from precursor fatty acids that are esterified to a complex glycerolipid (Ida Lager et al., 2013). The phospholipids of plant plasma membranes are produced in the endoplasmic reticulum. Most of these lipids get to the plasma membrane without passing through the secretory vesicular pathway. The transfer of phospholipids to the mitochondria and chloroplasts of plant cells also circumvents the secretory pathway and it has been suggested that lysophospholipids are transported via interaction sites between specific regions of the endoplasmic reticulum and the individual organelle, trailed by lysophospholipid acylation in the target organelle (Larsson et al., 2007).

\subsection{Untargeted Metabolomics of EC20 and TME-7 Cassava Roots using RPLC Detection}

The untargeted metabolites of EC-20 and TME- 7 cassava roots in untargeted metabolomics relative to EC-20 varieties using RPLC is given in Table 5. It identified digalactosyl diglyceride (DGDG), DGTS, linoleic, dihydrokaempferol and salicylic acid as the secondary metabolites that were upregulated (>2.0 folds) in the transgenic varieties. Dihydrokaempferol is a flavonoid and one of the secondary metabolites that was upregulated in EC-20 cassava varieties. Flavonoids are widely distributed in plants and are an important part of our diet due to their health-promoting benefits, including reduced risk of cancer and cardiovascular diseases (Price and Rhodes, 1997; Lin and Harnly, 2008). Flavonoids are a large group of phytochemicals that are derived from multiple branches of the shikimic acid pathway, one of the most-characterized secondary metabolic routes in plant systems (Khanam et al., 2012). The metabolic pathway of flavonoids has been generally acknowledged to be involved in the regulation mechanism of plants to several stress conditions (Agati et al., 2011]. The leading regulators of plant growth and defense are flavonoids, which are made and biosynthesized as a result of continuing natural selection and acclimatization processes (Jay-Allemand, 2015; Agati, 2012). Scavenging reactive oxygen species and growing tolerance to acclimatize to environmental variations are the predominant physiological functions of flavonoids as observed in tea plant, e.g., as antioxidants in photoprotection and this antioxidant activity is attributed to their reactions with free radicals as hydrogen donors (Zhang et al., 2017). Salicylic acid is an important signaling molecule in plants, it is a phenolic compound and has been found to be involved in the remediation of heavy metal toxicity, heat, osmotic and abiotic stress and drought response in plants (Vincent, 2011). According to Lu, 2009, salicylic acid act as an active calming agent for plants; also plays a very important role in the biochemical processes and regulations of the entire lifespan of the plant aside their biotic and abiotic functions. By understanding the objectives and its molecular modes of action in physiological processes could aid in the separation of the complex salicylic acid signaling network, favoring its vital function in plant health. Salicylic acid could also be responsible for the regulation of processes such as seed germination, vegetative growth, photosynthesis, respiration, thermogenesis, flower formation, seed production, senescence, and a form of cell death that is not linked to the hypersensitive response (Mariana, 2011). Molecular genetic tools could not unravel the mechanism underlying the ability of cassava to survive and produce under drought conditions (Pingjuan et al., 2015). Untargeted metabolomics approach used in this study has identified salicylic acid as one of the compounds responsible for the management of drought and other abiotic stresses in cassava (Lu, 2009).

\section{Conclusion}

This study showed that cassava varieties with high level of dry matter and starch are more prone to suffer postharvest physiological deterioration. This is associated with vascular streaking which will be more distributed up to the sclerenchyma region of the root cortex. The intermediary metabolites and non-nutrient metabolites identified with HILIC and RPLC are of biochemical importance to the plant and nutritionally relevant but need further assessment as required by law for genetically modified (GM) foods.

\section{Acknowledgements}

Experiments were carried out at Donald Danforth Plant Science Center (DDPSC) St. Louis, Missouri USA with the assistance of National Root Crops Research Institute (NRCRI), Umudike, Nigeria and funded by African Women in Agricultural Research and Development (AWARD).

\section{References}

Agati, G., Biricolti, S., Guidi, L., Ferrini, F., Fini, A., \& Tattini, M. (2011). The biosynthesis of flavonoids is enhanced similarly by UV radiation and root zone salinity in L. vulgare leaves. Journal of Plant Physiology, 
168(3), 204-12. https://doi.org/10.1016/j.jplph.2010.07.016

Agati, G., Azzarello, E., Pollastri, S., \& Tattini, M. (2012). Flavonoids as antioxidants in plants: location and functional significance. Plant Science, 196, 67-76. https://doi.org/10.1016/j.plantsci.2012.07.014

Aristizábal, J., \& Sánchez, T. (2007). Guía técnica para producción análisis de almidón de yuca. Boletín de Agrícolas de la FAO Roma. Food and Agriculture Organization of the United Nations, 163, 134.

Asare, A. P. (2004). Determination of dry matter content of cassava tubers. B.Sc dissertation, University of Cape Coast. Cape Coast, Ghana. p. 34.

Aslam, M., Majeed, S., Aslam, S., \& Irfan, J. (2017). Vitamins: Key role players in boosting up immune response. Vitam Miner, 6(1), 1000153.

Bayoumi, S. A., Rowan, M. G., Beeching, J. R., \& Blagbrough, I. S. (2010). Constituents and secondary metabolite natural products in fresh and deteriorated cassava roots. Phytochemistry, 71, 598-604. https://doi.org/10.1016/j.phytochem.2009.10.012

Beeching, J., Bull, S., Jones, K., \& Page, M. (2009). International Society for Tropical Root Crops (ISTRC). 15th Triennial ISTRC Symposium. p. 41-45.

Block, M., Dorne, A., Joyard, J., \& Douce, R. (1983). Preparation and characterization of membrane fractions enriched in outer and inner envelope membranes from spinach chloroplasts-biochemical characterization. Journal of Biology and Chemistry, 258, 13281-13286. https://doi.org/10.1016/S0021-9258(17)44113-5

Burri, B. (1997). Beta-carotene and human health: A review of current research. Nutrition Research, 17, 547-580. https://doi.org/10.1016/S0271-5317(97)00011-0

Cao, H., Wang, J., Dong, X., Han, Y., Ma, Q., Ding, Y., Zhao, F., Zhang, J., Chen, H., Xu, Q., Xu, J., \& Deng, X. (2015). Carotenoid accumulation affects redox status, starch metabolism, and flavonoid/anthocyanin accumulation in citrus. BMC Plant Biology, 15, 27. https://doi.org/10.1186/s12870-015-0426-4

Carvalho, L., Agustini, A., Anderson, J., Vieira, E., Souza, C., Chen, S., Schaal, B., \& Silva, J. (2016). Natural variation in expression of genes associated with carotenoid biosynthesis and accumulation in cassava (Manihot esculenta Crantz) storage root. BMC Plant Biology, 16, 133. https://doi.org/10.1186/s12870-016-0826-0

Churms, S. C. (1982). Carbohydrates in handbook of chromatography. CRC Press, FL.

Commisso, M., Strazzer, P., Toffali, K., Stocchero, M., \& Guzzo, F. (2013). Untargeted metabolomics: an emerging approach to determine the composition of herbal products. Computational and Structural Biotechnology, 4(5), e201301007. https://doi.org/10.5936/csbj.201301007

Dormann, P., \& Benning, C. (2002). Galactolipids rule in seed plants. Trends Plant Science, 7, 112-118. https://doi.org/10.1016/S1360-1385(01)02216-6

Edoh, N., Ogbokiri, H., Okoro, M., Egesi, C., Okogbenin, E., \& Njoku, D. (2014). Preliminary yield trial of selected high beta-carotene cassava genotypes at Umudike, Nigeria. Proceedings of the 48th Annual Conference of the Agricultural Society of Nigeria "Abuja 2014".

Eldahshan, O. A., \& Singab, A. B. (2013). Carotenoids. Journal of Pharmacognosy and Phytochemistry, 2(1), 2278-4136.

Eleazu, C. O., \& Eleazu, K. C. (2012). Determination of the proximate composition, total carotenoid, reducing sugars and residual cyanide levels of flours of 6 new yellow and white cassava (Manihot esculenta Crantz) varieties. American Journal of Food Technology, 7, 642-649. https://doi.org/10.3923/ajft.2012.642.649

Fraser, P. D., \& Bramley, P. M. (2004). The biosynthesis and nutritional uses of carotenoids. The Journal of Lipid Research, 43, 228-265. https://doi.org/10.1016/j.plipres.2003.10.002

Ga Hee J., Heon Woong K., Min Ki, L., So Young, J., Ram, B., Dong Jin, L., \& Jung, Bong K. (2016). Characterization and quantification of flavonoid glycosides in the Prunus genus by UPLC-DADQTOF/MS. Saudi Journal of Biological Sciences.

Grune, T., Lietz, G., Palou, A, Ross, C., Stahl, W., Tang, G., Thurnham, D., Yin, S., \& Biesalski, H. K. (2010). $B$-Carotene is an Important Vitamin A Source for Humans. American Society for Nutrition. https://doi.org/10.3945/jn.109.119024

Howitt, C. A., \& Pogson, B. J. (2006). Carotenoid accumulation and function in seeds and non green tissues. Plant Cell Environment, 29(3), 435-445. https://doi.org/10.1111/j.1365-3040.2005.01492.x 
Ida Lager, J, L., Xue-Rong, Z., Katarzyna, J., Michael, K., Peng, W., Jitao, Z., ... Sten, S. (2013). Plant Acyl-CoA:Lysophosphatidylcholine Acyltransferases (LPCATs) Have Different Specificities in Their Forward and Reverse Reactions. The Journal of Biological Chemistry, 288(52), 36902-36914. https://doi.org/10.1074/jbc.M113.521815

Jay-Allemand, C., Tattini, M., \& Gould, K. (2015). New evidence for the functional roles of secondary metabolites in plant-environment interactions. Environ Experimental Botany, 119, 1-3. https://doi.org/10.1016/j.envexpbot.2015.06.011

Joyard, J., Marechal, E., Miege, C., Block, M., Dorne, A., \& Douce, R. (1998). Structure, distribution and biosynthesis of glycerolipids from higher plant chloroplasts. In P. A. Siegenthaler \& N. Murata (Eds.), Lipids in photosynthesis: Structure, function and genetics (pp. 21-52). Kluwer Academic Publishers, Dordrecht, The Netherlands. https://doi.org/10.1007/0-306-48087-5_2

Khanam, U. K. S., Oba, S., Yanase, E., \& Murakami, Y. (2012). Phenolic acids, flavonoids and total antioxidant capacity of selected leafy vegetables. Journal of Functional Foods, 4, 979-987. https://doi.org/10.1016/j.jff.2012.07.006

Larsson, E. K., Magnus, K., Henrik, T., \& Andelius, A. S. (2007). LysoPC acyltransferase/PC transacylase activities in plant plasma membrane and plasma membrane-associated endoplasmic reticulum. BMC Plant Biology, 7, 64. https://doi.org/10.1186/1471-2229-7-64

Lin, L. Z., \& Harley, J. M. (2008). Phenolic compounds and chromatographic profiles of pear skins (Pyrus spp.). Journal of Agricultural Food Chemistry, 56, 9094-9101. https://doi.org/10.1021/jf8013487

Londesborough, J. (2001). Fermentation of maltotriose by brewer's and baker's yeast. Biotechnology, 23, 1995-2000. https://doi.org/10.1023/A:1013722711620

Lu, H. (2009). Dissection of salicylic acid-mediated defense signaling networks. Plant Signal Behavior, 4, 713-7. https://doi.org/10.4161/psb.4.8.9173

Mariana, R-S. V., \& Javier, P.(2011). Salicylic acid beyond defence: its role in plant growth and development. Journal of Experimental Botany, 62(10), 3321-3338. https://doi.org/10.1093/jxb/err031

Masuda, S., Harada, J., Yokono, M., Yuzawa, Y., Shimojima, M., ... Ohta, H. (2011). A Monogalactosyldiacylglycerol Synthase Found in the Green Sulfur Bacterium Chlorobaculum tepidum. Reveals Important Roles for Galactolipids in Photosynthesis. Plant Cell physiology, 23, 2644-2658. https://doi.org/10.1105/tpc.111.085357

Morante, N., Sanchez, T., Ceballos, H., Calle, F., Pérez, J. C., ... Fregene, M. (2010). Tolerance to postharvest physiological deterioration in cassava roots. Crop Sci., 50, 1333-1338. https://doi.org/10.2135/cropsci2009.11.0666

Nisar, N., Li, L., Lu, S., Khin, N. C., \& Pogson, B. J. (2015). Carotenoid Metabolism in Plants. Molecular Plant, 8, 68-82. https://doi.org/10.1016/j.molp.2014.12.007

Pingjuan, Z., Pei, L., Jiaofang, S., Chunqiang, L., Wang, B., Xin, G., Bin, Y., Yiji, X., \& Ming, P. (2015). Analysis of different strategies adapted by two cassava cultivars in response to drought stress: ensuring survival or continuing growth. Journal of Experimental Botany, 66(5), 1477-1488. https://doi.org/10.1093/jxb/eru507

Price, K. R., \& Rhodes, M. J. C. (1997). Analysis of the major flavonol glycosides present in four varieties of onion (Allium cepa) and changes in composition resulting from autolysis. Journal Science of Food Agric., 74, 331-339. https://doi.org/10.1002/(SICI)1097-0010(199707)74:3<331::AID-JSFA806>3.0.CO;2-C

Sakurai, I., Mizusawa, N., Wada, H., \& Sato, N. (2007). Roles of digalactosyldiacylglycerol in photosynthesis. Plant Cell Physiology, 48, 172-180.

Sánchez, T., Chavez, A. L., Ceballos, H., Rodriguez-Amaya, D. B., Nestel, P., \& Ishitani, M. (2006). Reduction or delay of post-harvest physiological deterioration in cassava roots with higher carotenoid content. Journal of the Science of Food and Agriculture, 86, 634-639. https://doi.org/10.1002/jsfa.2371

Uarrota, V. G., Eduardo da Costa, N., Luiz, A. M., Enilto de Oliveira, N., Bianca, C., ... Marcelo, M. (2015). Toward better understanding of postharvest deterioration: biochemical changes in stored cassava (Manihot esculenta Crantz) roots. Food Science and Nutrition, 4(3), 409-422. https://doi.org/10.1002/fsn3.303

Vincent, M. R. S., \& Plasencia, J. (2011). Salicylic acid beyond defence: its role in plant growth and development. Journal of Experimental Botany, 62, 3321-38. https://doi.org/10.1093/jxb/err031 
Vinayavekhin, N., \& Saghatelian, A. (2010). Untargeted Metabolomics. Molecular Biology, Harvard University, Cambridge, Massachusetts, USA. https://doi.org/10.1002/0471142727.mb3001s90

Zhang, Q., Meiya, L., \& Jianyun, R. (2017). Metabolomics analysis reveals the metabolic and functional roles of flavonoids in light-sensitive tea leaves. BMC Plant Biology, 17, 64. https://doi.org/10.1186/s12870-017-1012-8

Zidenga, T., Leyva-Guerrero, E., Moon, H., Siritunga, D., \& Sayre, R. (2012). Extending cassava root shelf life via reduction of reactive oxygen species production. Plant Physiology, 159, 1396-1407. https://doi.org/10.1104/pp.112.200345

Zastrow, C. R., Mattos, M. A., Hollatz, C., \& Stambuk, B. (2000). Maltotriose metabolism by Saccharomyces cerevisiae. Biotechnology, 22, 455-459. https://doi.org/10.1023/A:1005691031880

\section{Copyrights}

Copyright for this article is retained by the author(s), with first publication rights granted to the journal.

This is an open-access article distributed under the terms and conditions of the Creative Commons Attribution license (http://creativecommons.org/licenses/by/4.0/). 